\title{
Article \\ Comparative Molecular and Metabolic Profiling of Two Contrasting Wheat Cultivars under Drought Stress
}

\author{
Hind Emad Fadoul ${ }^{1,2, *}$, Félix Juan Martínez Rivas ${ }^{3}{ }^{(0}$, Kerstin Neumann ${ }^{4} \mathbb{D}$, Salma Balazadeh ${ }^{3,5}$, \\ Alisdair R. Fernie ${ }^{3,6}$ and Saleh Alseekh ${ }^{3,6, * \text { (D) }}$ \\ 1 Department of Botany, Faculty of Science, University of Khartoum, Khartoum 11115, Sudan \\ 2 Department of Biology, University of Toronto Mississauga, Mississauga, ON L5L 1C6, Canada \\ 3 Max Planck Institute of Molecular Plant Physiology, Am Mühlenberg 1, 14476 Potsdam-Golm, Germany; \\ rivas@mpimp-golm.mpg.de (F.J.M.R.); balazadeh@mpimp-golm.mpg.de (S.B.); \\ fernie@mpimp-golm.mpg.de (A.R.F.) \\ 4 Leibniz Institute of Plant Genetics and Crop Plant Research (IPK), Corrensstrasse 3, 06466 Seeland, Germany; \\ neumannk@ipk-gatersleben.de \\ 5 Institute of Biology, Leiden University, Sylviusweg 72, 2333 BE Leiden, The Netherlands \\ 6 Center of Plant Systems Biology and Biotechnology, Ruski Blvd. 139, 4000 Plovdiv, Bulgaria \\ * Correspondence: hind.emad@utoronto.ca (H.E.F.); alseekh@mpimp-golm.mpg.de (S.A.); \\ Tel.: +49-331-567-8211 (S.A.)
}

Citation: Fadoul, H.E.; Martínez Rivas, F.J.; Neumann, K.; Balazadeh, S.; Fernie, A.R.; Alseekh, S. Comparative Molecular and Metabolic Profiling of Two Contrasting Wheat Cultivars under Drought Stress. Int. J. Mol. Sci. 2021, 22, 13287. https://doi.org/10.3390/ ijms222413287

Academic Editors: Ricardo Aroca, Roberto Papa, Roberto Papa and Valerio Di Vittori

Received: 17 November 2021 Accepted: 7 December 2021 Published: 10 December 2021

Publisher's Note: MDPI stays neutral with regard to jurisdictional claims in published maps and institutional affiliations.

Copyright: (c) 2021 by the authors. Licensee MDPI, Basel, Switzerland. This article is an open access article distributed under the terms and conditions of the Creative Commons Attribution (CC BY) license (https:// creativecommons.org/licenses/by/ $4.0 /)$.

\begin{abstract}
Drought is one of the most important threats to plants and agriculture; therefore, understanding of the mechanisms of drought tolerance is crucial for breeding of new tolerant varieties. Here, we assessed the effects of a long-term water deficit stress simulated on a precision phenotyping system on some morphological criteria and metabolite traits, as well as the expression of drought associated transcriptional factors of two contrasting drought-responsive African wheat cultivars, Condor and Wadielniel. The current study showed that under drought stress Wadielniel exhibits significant higher tillering and height compared to Condor. Further, we used gas chromatography and ultra-high performance liquid chromatography mass-spectrometry to identify compounds that change between the two cultivars upon drought. Partial least square discriminant analysis (PLS-DA) revealed that 50 metabolites with a possible role in drought stress regulation were significantly changed in both cultivars under water deficit stress. These metabolites included several amino acids, most notably proline, some organic acids, and lipid classes PC 36:3 and TAG 56:9, which were significantly altered under drought stress. Here, the results discussed in the context of understanding the mechanisms involved in the drought response of wheat cultivars, as the phenotype parameters, metabolite content and expression of drought associated transcriptional factors could also be used for potential crop improvement under drought stress.
\end{abstract}

Keywords: wheat; drought tolerance; JUNGBRUNNEN1 (JUB1); metabolomics; lipids

\section{Introduction}

Wheat (Triticum aestivum L.) is the most cultivated crop worldwide in terms of cultivated area and grain acreage (FAO, 2020), and accounts for $20 \%$ of the carbohydrate and protein sources in the human diet [1]. In the context of global climate change, crop tolerance to abiotic stresses such as drought, heat, salt, water logging, and freezing is becoming more critical to ensure food access worldwide. Environmental stresses and climatic extremes represent the main constraints of crop productivity. Wheat production is highly affected by environmental stresses; changes in weather conditions are affecting crops in Europe and in the Indian subcontinent, where the increase in the temperature is reducing wheat yield up to $0.2-0.5 \mathrm{t} \mathrm{ha}^{-1}[2,3]$. Moreover, up to $40 \%$ of the inter-annual wheat yield variability in the period 1980-2010 is attributed to extreme weather changes, such as heat waves and periods of drought [4]. 
Among the abiotic stresses that affect plants, drought is one of the main factors which reduces leaf and root growth, as well as yield [5]. With an estimated third of the total cultivated area affected by drought stresses, improving the knowledge related to the molecular mechanisms underlying drought tolerance is a critical factor needed for the development of new drought tolerant genotypes [6,7]. Drought tolerance includes a wide range of genetic, biochemical, and physiological adaptations displayed by plants to cope with this stress. One of the responses is to synthetize new proteins that help to maintain homeostasis and water potential in the cell. This change in the transcriptome is driven by the expression of transcription factors (TFs), which regulate the expression of some stress resistant genes [8]. Different TF families have been related with the regulation of drought responses in wheat such as NAM, ATAF, and CUC (NAC), dehydration-responsive element-binding (DREB) factors, basic leucine zipper (bZIP), MYB, and WRKY [9].

Another response used by plants is to reconfigure its metabolic networks to acclimate to the stress condition. Thus, metabolic studies have been performed to decipher how plants adapt to new conditions. Higher levels of some metabolites, such as proline, different sugars, or polyols are increased not only in drought, but also in response to other abiotic stresses, revealing that plants present a core metabolic response to face different stresses [10]. In wheat, higher levels of metabolites, such as tricarboxylic acid intermediates, sugars, and amino acids, have been described in response to drought [11,12]. Moreover, lipids also respond to stresses in plants, as these conditions induce fatty acid saturation, thus increase the rigidity of the membrane. In addition, reactive oxidative species (ROS), produced due to stress conditions, will cause oxidative damage to the membrane, causing a malfunction in cell membranes $[13,14]$. Cell membranes are of the first receptors of drought stress, and they can protect the cell by changing stress perception and rigidity of the cell structure. For example, changes in membrane lipid such as phosphate dylcholine (PC), phoshatidylethanolamine (PE), digalactosyldiacylglycerol (DGDG), and monogalactosyldiacylglycerol (MGDG) may compromise the response against drought [15]. On the other hand, under water stress, a decrease in membrane lipid content was observed, and PC was largely degraded [16].

In this work, we have studied the different drought response of two wheat cultivars contrasting in their drought tolerance and extensively used by African farmers, including physiological responses and the expression patterns of TFs related to drought, as well as metabolic profiling. The information provided will improve our knowledge concerning the drought response in wheat that contributes to a better understanding of the basis of plant stress responses.

\section{Results}

\subsection{Phenotypic Alteration on Water Limitation Stress}

Regarding tiller numbers, both cultivars presented a similar pattern with no differences in control treatment, and plants formed in average one tiller at DAS 22 (day after sowing 22, T0) to five tiller at DAS53 (Figure 1A). After the water deficit treatment started, Condor (the drought sensitive cultivar) stopped tillering, showing no further increase from T0 until the end, with around one tiller across the whole treatment. Meanwhile, Wadielniel (the drought tolerant cultivar) continued to form tillers after T0, up to three at DAS53 (Figure 1A). After flowering, ear formation did not show any differences between the two cultivars in the evaluated period, with both cultivars producing around one per plant in drought. Still, Wadielniel presented a slightly higher number of ears under the stress condition due to late formation of secondary ears, but this was not statistically significant (1 vs. 1.4 on average for Condor and Wadielniel, respectively). However, these secondary ears were sterile and produced no seeds. No differences in ear number were observed in the control treatment (Figure 1B). 


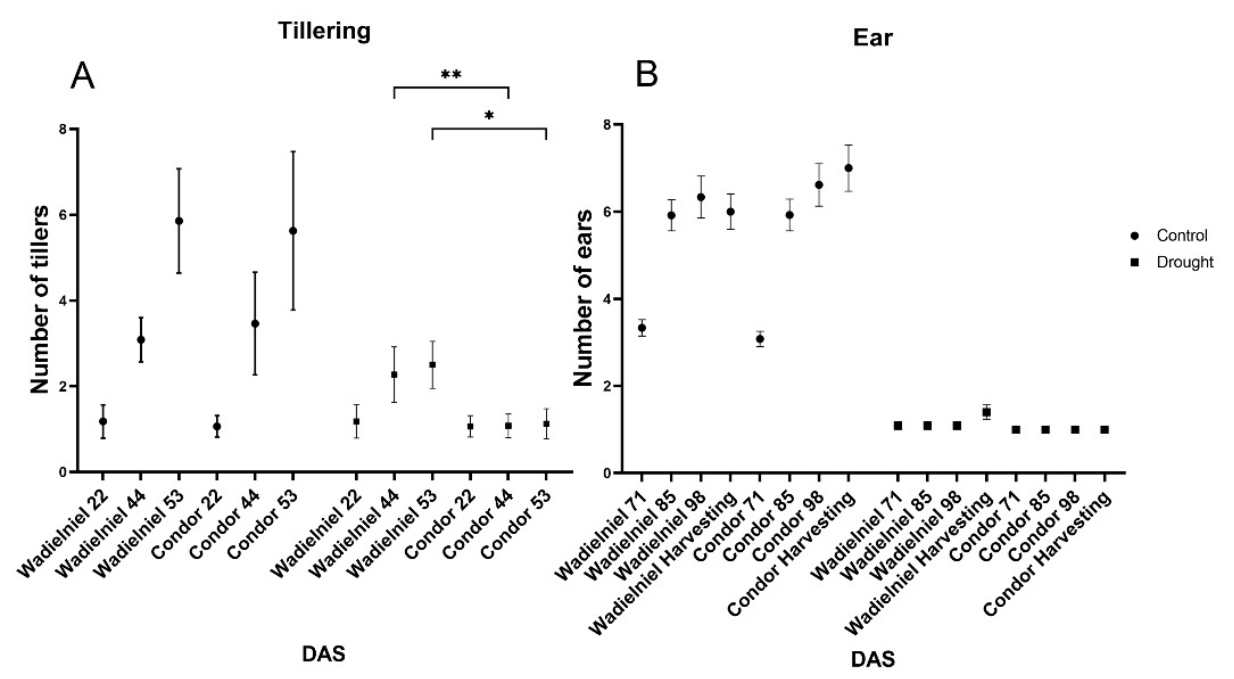

Figure 1. Phenotypical traits in wheat cultivars in response to water deficit stress. (A). Number of tillers observed and (B) number of ears in both cultivars. Samples were taken in different timepoints DAS 22, 44, and 53 for tillering and DAS 71, 85, 98, and at harvesting day for ear number. Ear number was inferred from visual inspection of images taken by the phenotyping system. Bars show mean $\pm \mathrm{SD}$. Statistical significances are determined by a Student $t$-test between cultivars in the same experimental conditions $*<0.05,{ }^{* *} p<0.01$.

The time of heading, BBCH55 [17] was inferred from inspecting the images. Under control conditions, no difference was seen with this treatment, as both cultivars presented a heading time of around 57 days (Figure 2). Both cultivars responded to water deficit stress by earlier heading compared to the control, with this being more pronounced in Condor, which headed, on average, three days earlier than cv. Wadielniel (Figure 2). This difference indicates that Condor reacts more sensitively to drought, using early heading as a stress escape strategy.

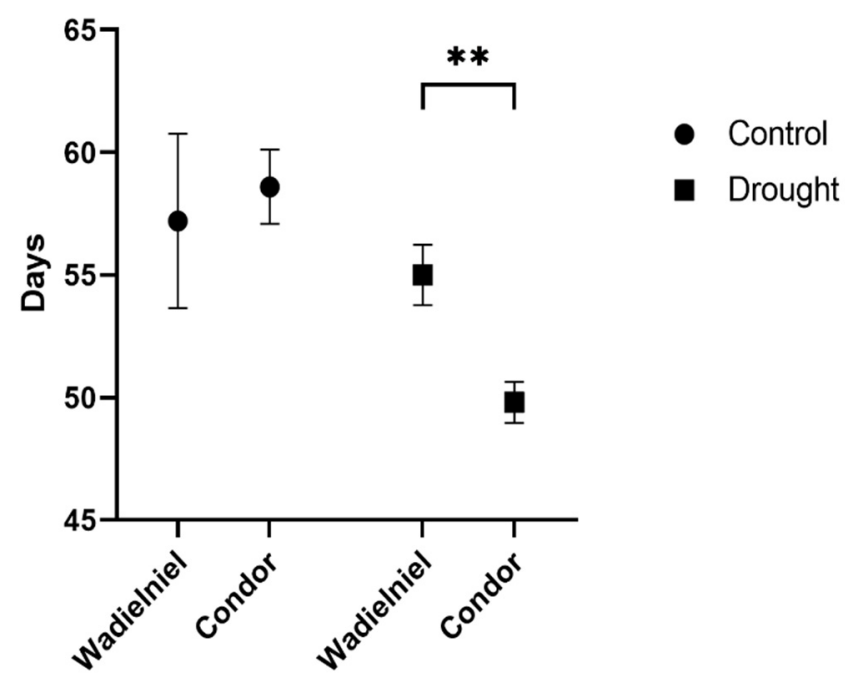

Figure 2. Days of heading for both cultivars in control and water limitation condition as inferred from pictures. Bars show mean $\pm \mathrm{SD}$. Statistical significances are determined by a Student $t$-test between cultivars in the same experimental conditions ${ }^{* *} p<0.01$.

The drought tolerant cultivar Wadielniel was significantly taller in both treatments, with a difference of approximately $5 \mathrm{~cm}$ (Figure 3A). In contrast, Condor had a longer peduncle and awn length in both control and water deficit, as well as a longer last internode (Figure 3B,C). Wadielniel had a tendency of maintaining more biomass under stress 
(Figure 3D, $p=0.07$ ) than Condor. Plant straw weight was significantly higher under water deficit for Wadielniel, due to the higher tillering (Figure 3E).

$$
\text { A }
$$

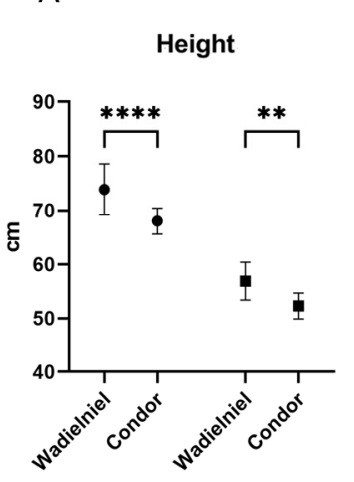

B

Peduncle length

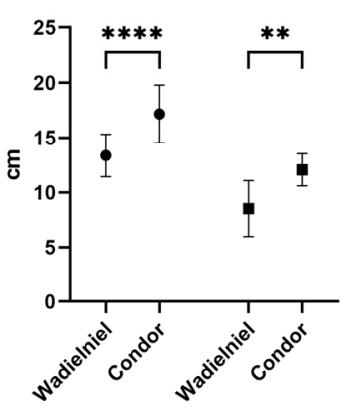

E

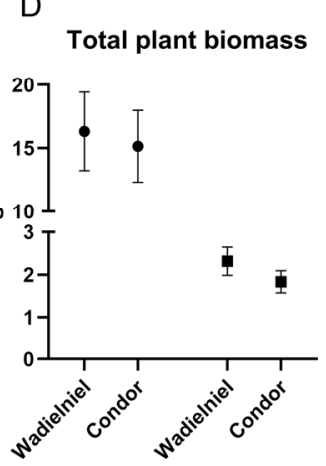

Straw biomass

C

Last internode length

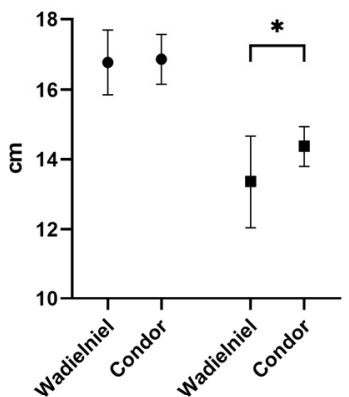

- Control

- Drought

Figure 3. Different phenotypic parameters measured in both cultivars in response to water limitation. (A). Total plant height in $\mathrm{cm},(\mathbf{B})$. Peduncle length in $\mathrm{cm},(\mathbf{C})$. Last internode length, (D). Total plant biomass as sum of straw and grain biomass in grams, (E). Straw biomass in grams. Bars show mean $\pm \mathrm{SD}$. Statistical significances are determined by a Student $t$-test between cultivars in the same experimental conditions ${ }^{*} p<0.05,{ }^{* *} p<0.01,{ }^{* * * *} p<0.0001$.

While Wadielniel developed more spikelets per ear than Condor under both control and drought conditions, Condor was able to produce more seeds per spikelet in both treatments (Table 1). As a consequence, plant grain number and grain number of the main ear did not significantly differ in the two cultivars, although there was a tendency for a higher number of grains in the main ear for Condor $(p=0.08)$ in control (Table 1$)$.

Table 1. Yield related characteristics presented as mean \pm SD. Statistical significances are determined by a Student $t$-test between cultivars in the same experimental conditions. ${ }^{*} p<0.05,{ }^{* * * *} p<0.0001$.

\begin{tabular}{clccccc}
\hline Genotype & & Spikelet Number & Spikelet with Seeds & $\begin{array}{c}\text { Seeds per } \\
\text { Spikelet }\end{array}$ & $\begin{array}{c}\text { Total Plant } \\
\text { Grain Number }\end{array}$ & $\begin{array}{c}\text { Grain Number } \\
\text { of Main Ear }\end{array}$ \\
\hline \multirow{2}{*}{ Wadielniel } & Control & $19.63 \pm 1.82^{*}$ & $17.56 \pm 2.39$ & $1.79 \pm 0.54$ & $219.85 \pm 40.87$ & $35.31 \pm 11.22$ \\
& Drought & $18.67 \pm 1.67^{* * * *}$ & $16.82 \pm 2.23^{* * * *}$ & $1.51 \pm 0.35$ & $30.42 \pm 9.47$ & $28.17 \pm 7.20$ \\
\hline \multirow{2}{*}{ Condor } & Control & $17.44 \pm 1.76$ & $16.50 \pm 2.31$ & $2.26 \pm 0.41^{*}$ & $217.15 \pm 25.07$ & $40.67 \pm 9.48$ \\
& Drought & $15.15 \pm 0.9$ & $13.38 \pm 0.96$ & $1.87 \pm 0.18^{*}$ & $28.38 \pm 3.78$ & $28.38 \pm 3.78$ \\
\hline
\end{tabular}

The thousand-kernel weight (TKW) of the main ear and the average seed area were significantly higher in Wadielniel both under control and drought conditions, as well as seed width and length (Table 2). 
Table 2. Seed parameters presented as means \pm SD. Statistical significances determined by a Student $t$-test between cultivars in the same experimental condition. ${ }^{*} p<0.05,{ }^{* *} p<0.01,{ }^{* * *} p<0.001$.

\begin{tabular}{cccccc}
\hline Genotype & & TKW $(\mathbf{g})$ & Seed Area $\left.\mathbf{( m m}^{\mathbf{2}}\right)$ & Seed Width $(\mathbf{m m})$ & Seed Length $(\mathbf{m m})$ \\
\hline \multirow{2}{*}{ Wadielniel } & Control & $46.15 \pm 4.94^{* *}$ & $15.88 \pm 1.03^{* *}$ & $3.55 \pm 0.15^{*}$ & $6.24 \pm 0.20^{* * *}$ \\
& Drought & $35.55 \pm 8.24^{*}$ & $13.39 \pm 1.58^{*}$ & $3.18 \pm 0.23$ & $6.02 \pm 0.24^{*}$ \\
\hline \multirow{2}{*}{ Condor } & Control & $40.32 \pm 5.11$ & $14.45 \pm 1.10$ & $3.38 \pm 0.21$ & $5.94 \pm 0.16$ \\
& Drought & $30.72 \pm 3.09$ & $12.41 \pm 0.73$ & $2.98 \pm 0.14$ & $5.78 \pm 0.17$ \\
\hline
\end{tabular}

In summary, Wadielniel does not clearly emerge as the better genotype at maturity on a single plant basis (no difference in grain yield), but some grain yield components were increased as compared to Condor, such as higher ear number, higher straw weight, and a trend of higher total biomass at maturity. The drought tolerant cultivar showed a higher tillering capacity under drought and did not react with drastic earlier heading as was seen for Condor.

\subsection{Relative Expression of Drought Related Genes}

As part of the plant response to drought, the expression of several TFs is modulated to cope with the adverse conditions. In that sense, we studied the expression of TFs related with drought response. TFs such as the TaJUB1/NAC042 orthologue of Arabidopsis thaliana ANAC042, as well as PEPKR2, which encodes a serine/threonine protein kinase, increased expression in response to drought in the tolerant cultivar Wadielniel, while no change was observed in Condor (Figure 4A,B). We measured the three copies of NAC55 found in the three chromosomes of wheat. While NAC55A increased expression in Condor, $N A C 55 B$ and $N A C 55 D$ were decreased in Wadielniel in response to water deficit stress (Figure 4C-E). Moreover, the expression of the delta-1-pyrroline-5-carboxylate synthase (P5CS) gene involved in proline biosynthesis, as a well-known osmolyte was upregulated in Wadielniel, but downregulated in Condor (Figure 4F), while in contrast to NAC55, all three copies of $N A C 7$ increased their expression in Wadielniel (Figure 4G-I).

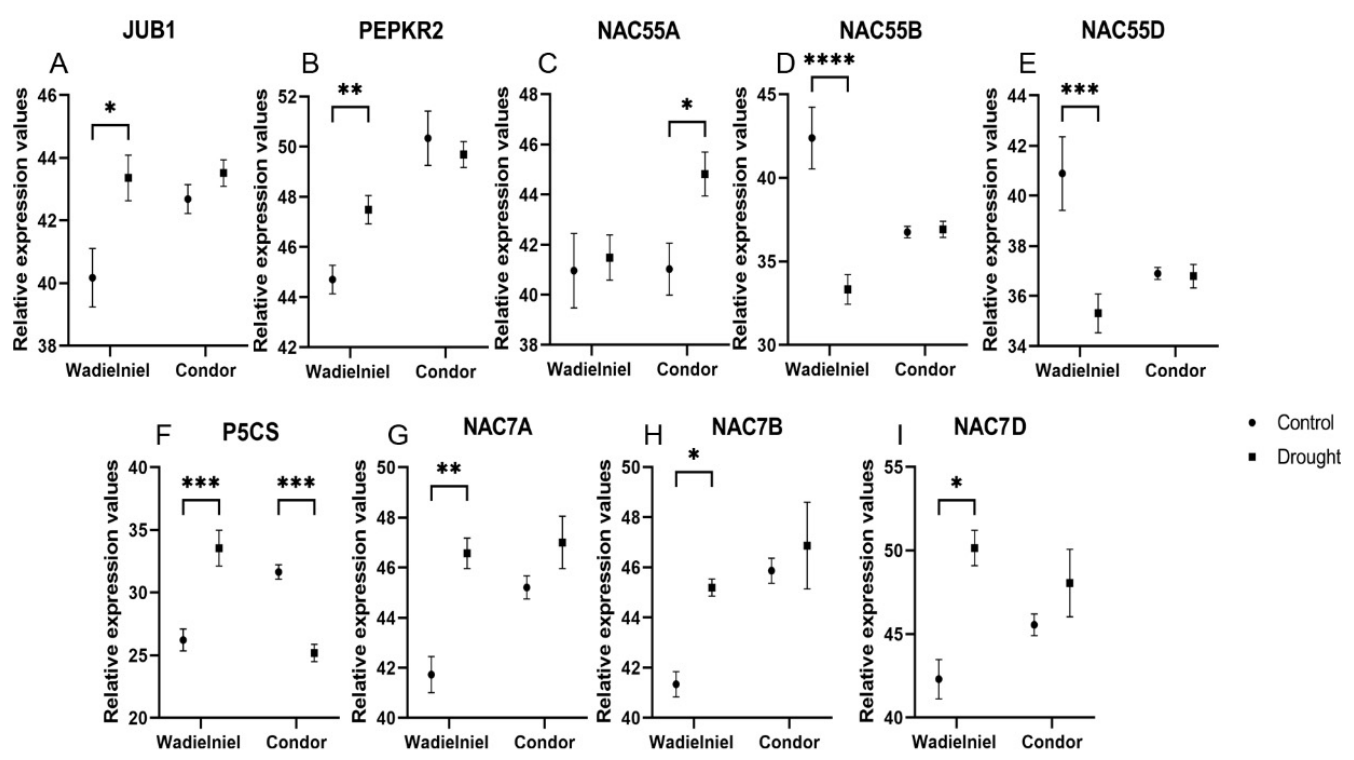

Figure 4. Relative expression data for selected genes studied by qRT-PCR. (A-I) Wheat genes selected for expression analysis. The primers used are listed in Table S2. The Y axis indicates expression level (40- $\Delta \mathrm{Ct}$ ). Values are expressed between an arbitrary value of 40 and $\Delta \mathrm{CT}$, so a high $40-\Delta \mathrm{Ct}$ value indicates a higher expression level. Statistical significances were determined with a Student $t$-test versus the control in the same cultivar. ${ }^{*} p<0.05,{ }^{* *} p<0.01,{ }^{* * *} p<0.001,{ }^{* * * *} p<0.0001$. 


\subsection{Metabolite Profiling under Drought Stress}

To explore the response upon drought in the two wheat cultivars, we used gas chromatography-mass spectrometry (GC-MS) and ultra-high performance liquid chromatography-mass spectrometry (UPLC-MS) to determine the levels of $>150$ compounds in leaf tissue. We were able to identify and quantify a total of 74 metabolites, including amino acids $(28 \%)$, organic acids $(23 \%)$, sugars $(10 \%)$, polyamines, and nucleobases. For lipids, we were able to determine up to 78 different compounds. Among these highlights, 26 triacylglycerides TAGs ( $33 \%$ of the total) and 16 phosphatidylcholines PCs (20\% of the total), the two main categories, were identified. To identify metabolites associated with the drought condition, principal component analysis (PCA) was performed (Figure 5). The first and the second components explained $57.8 \%$ and $5.5 \%$ of the metabolite variance, respectively.

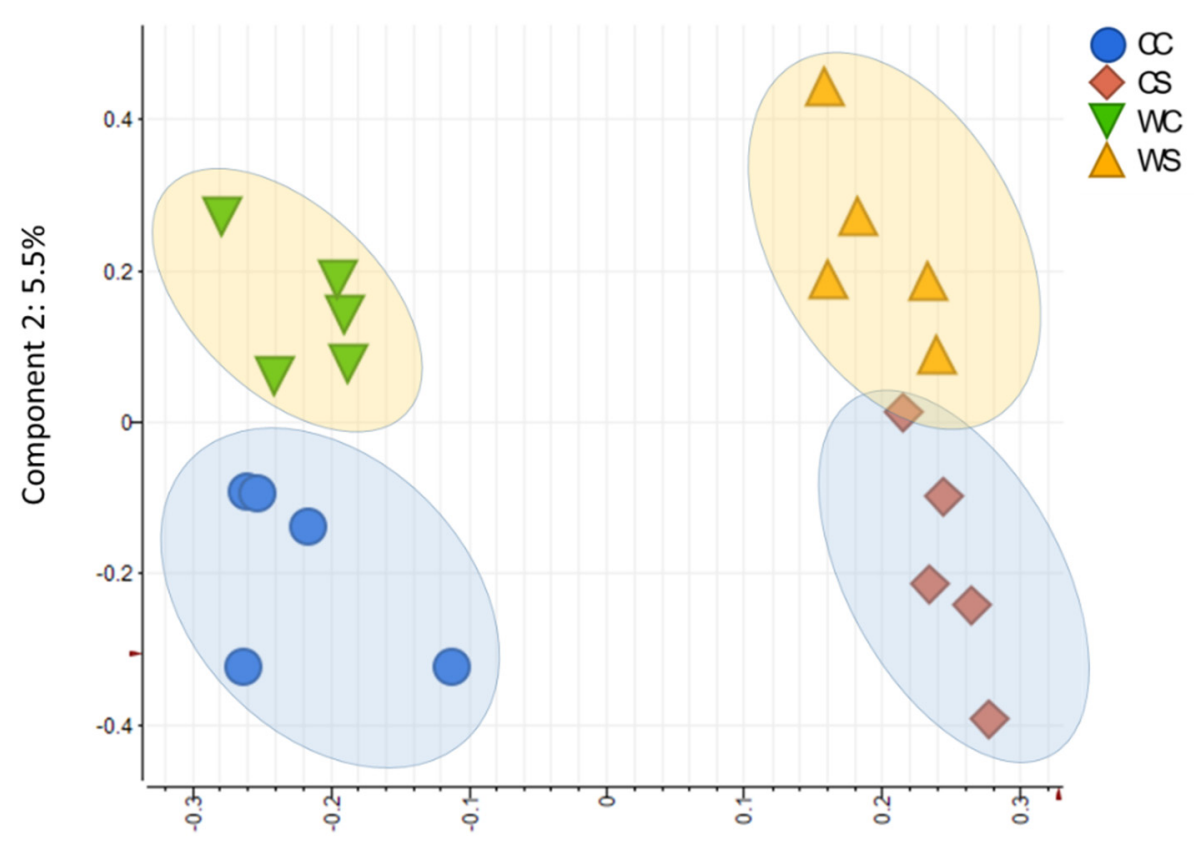

Component 1: $57.8 \%$

Figure 5. Partial least squares discriminant analysis (PLS-DA) based on both primary metabolites and lipids. CC, Condor Control; CS, Condor Stress; WC, Wadielniel Control; WS, Wadielniel Stress. Data from five independent biological replicates were used to perform the PLS-DA.

The results demonstrated that under normal conditions, no significant differences between the two cultivars were observed, as shown in the PCA (Figure 5). On the other hand, a total of 42 metabolites in Condor and 26 in Wadielniel were significantly changed $(p<0.05)$ under drought conditions (Table S1). Some metabolites exhibited a similar change in response to drought stress in both cultivars, i.e., a significant increase in the concentrations of free amino acids (proline, glycine, isoleucine, leucine, phenylalanine, tyrosine, valine, serine-o-acetyle, and glutamine), organic acids (glycolic acid, galacturonic acid and citric acid), and other compounds (G-1-P, G-3-P, erythrose, erythritol) were observed (Figure 6, Table S1). Meanwhile, a significant decrease of quinic acid, 3-caffeoyl-quinic acid, myo-inositol, and homo-serine were also observed. The metabolites that changed most significantly upon drought were proline with a 5-fold change and quinic acid (-7.4-fold change). For lipids, 35 in Condor and 33 Wadielniel were significantly changed in response to drought (Table S1). Among them, we observed a general higher concentration of TAGs in both cultivars, especially TAG 50:3 and TAG 54:9, but a lower concentration of PCs, such as 38:3 and 38:4 (Figure S1). Finally, we investigated correlations between and within different metabolite classes and phenotypic traits (Figure 7A, and Table S3). This revealed that many 
metabolites are highly associated within the network. Interestingly, strong correlations $(>90 \%)$ were observed between some of the phenotypic traits and metabolites content (Figure 7B). For example, the amino acid proline was negatively correlated with total plant biomass, grain number, ear number, and straw biomass. In addition, the lipid classes PC 36:3 and TAG 56:9 were correlated with total plant biomass, straw biomass and total grain number (Figure 7B). This indicates that these compounds could be used as markers to assess the response to drought in wheat plants.
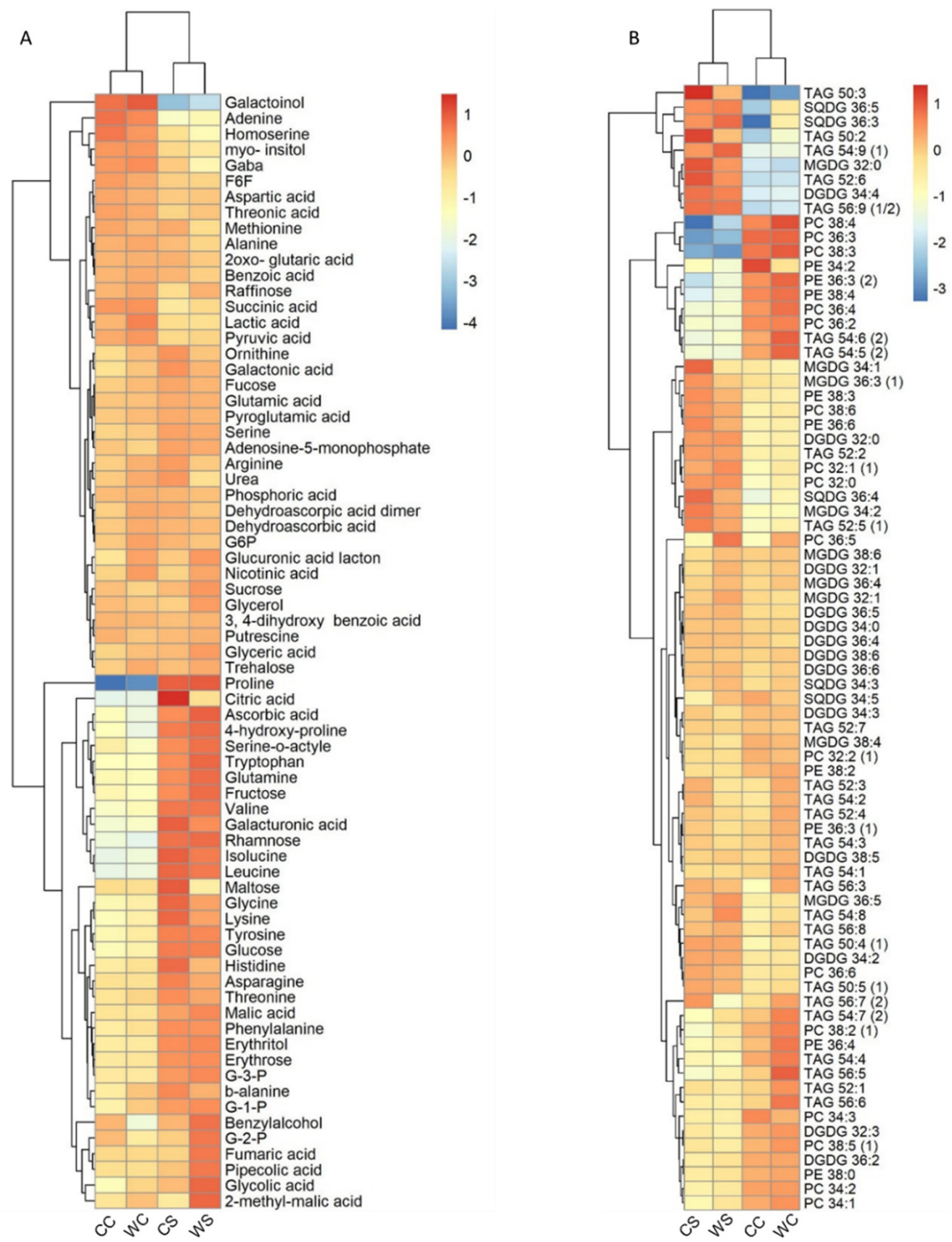

Figure 6. Heat map of primary metabolites measured by GC-MS (A) and lipids measured by UPLCMS (B). Values correspond to log2-fold changes in relation to control samples of the same genotype. Full data sets are provided in Table S1. 

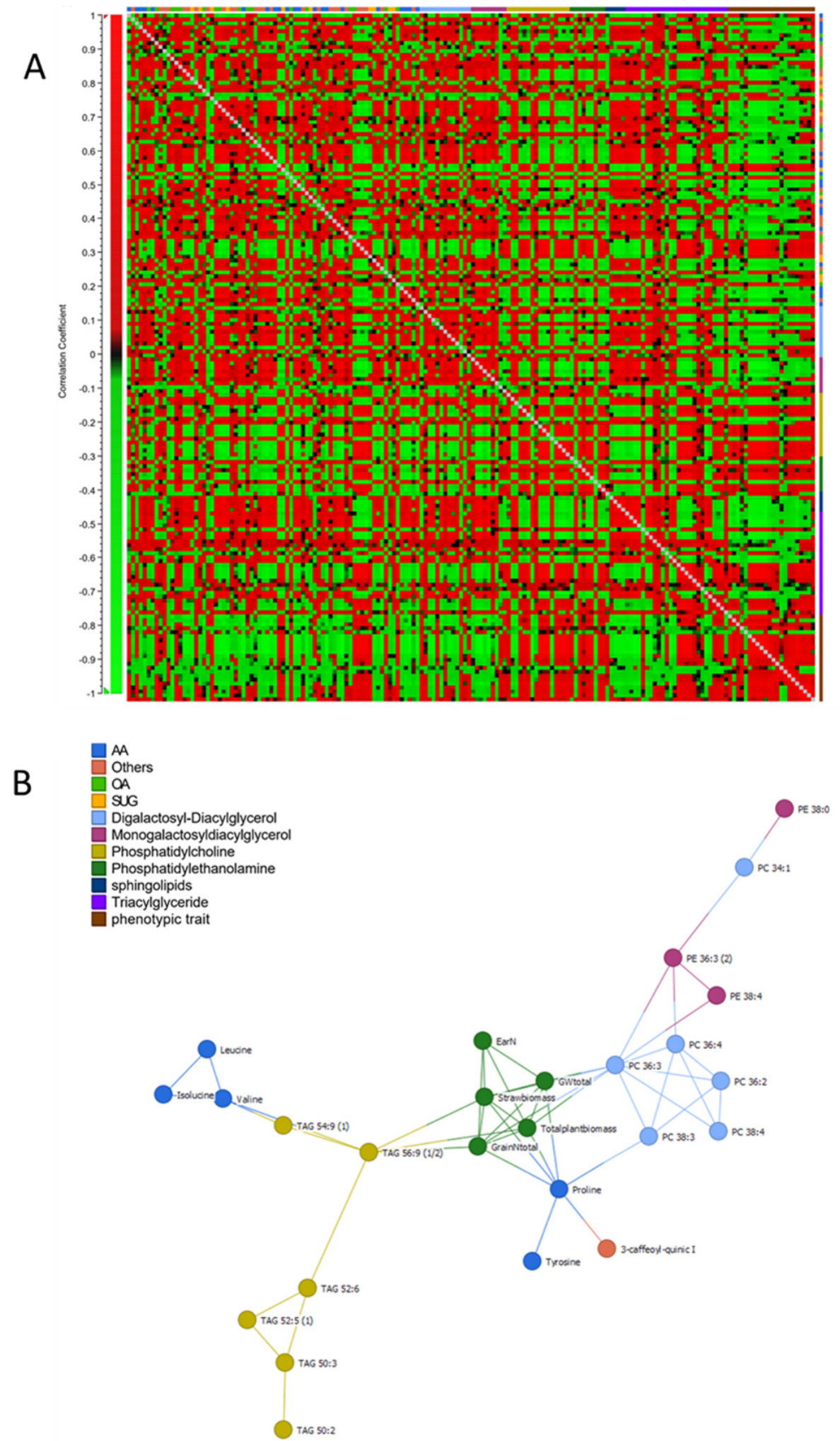

Figure 7. (A) Correlation analysis between and within phenotypic and metabolic traits. (B) Plan showing correlation network analysis with $\geq 90 \%$, each node represents a metabolite or a plant phenotypic trait, edges connecting two nodes show an association between two traits. Full data represent in Table S3. 


\section{Discussion}

Knowledge concerning the mechanisms underlying drought tolerance is important for the development of drought tolerant wheat genotypes. In this study, phenological, transcriptional, and metabolic responses of two wheat cultivars with contrasting drought stress responses were investigated under control and drought stress conditions.

\subsection{Measures of Growth and Yield Related Traits in Response to Drought}

The impact of drought on plant development depends on the timing of its occurrence. In the tillering phase, the number of tillers per plant and biomass is reduced [18]; during stem elongation, and the plant height is affected [5]; when water deficit stress occurs around the flowering stage, the seed set is negatively affected [19], while drought during the grain filling phase reduces the TKW [20,21]. In our experiments, the stress started in the early tillering stage, and lasted until seed maturity. Accordingly, all of these traits were reduced in drought compared to control treatment. While Wadieniel could continue tillering, albeit less than in control, Condor completely stopped tillering due to the ongoing drought. On the one hand, Duggan et al. (2000) showed that under drought stress, only small differences in grain yield were observed, while high kernel number, through greater tillering, was shown to be an adaptation to low-stress conditions [22]. Others indicated that some drought tolerant cultivars (e.g., Excalibur) found to be more responsive to cyclic drought stress, produced more tillers per se and aborted them under drought stress, and showed rapid recovery after re-watering [23].

Moreover, water deficit stress caused an earlier flowering in both cultivars, but this was much stronger in the sensitive cultivar Condor. However, in the control treatment, there was no statistical difference in flowering time. This indicates that Condor reacts more sensitive to stress and trying to escape from it by a faster development. It has been shown that early flowering and maturity are effective drought escape mechanisms in plants including cereal crops such as wheat [24]. It is argued that plants under water limitation condition attempt to survive by completing their life cycle quickly [25], and the genotypes sensitive to stress start to respond to drought at germination and tillering stage by producing less plants and aborting initial tillers. Khan et al. (2012) proposed that the reason behind reduced growth and early flowering under severe heat stress could be attributed to limitations of resources and the sensitivity of metabolic processes that have limit the ability to effectively utilize available resources [26].

In conclusion, the drought tolerant cultivar did show improved performance under drought conditions, compared with the sensitive cultivar, also under controlled greenhouse conditions in a pot experiment on a phenotyping platform. However, the yield advantage seen in the field was not achieved in this pot study. It might be that the stress conditions were too harsh to well differentiate the genotypes in their yield response. The threshold of $20 \%$ PAW (plant available water) was chosen based on the results of screening a diverse barley collection on the very same platform [18]. The stop of growth in barley occurred in average at $21 \%$ PAW. However, in this older setup, plants were re-watered after a $\sim 3$ weeks drought period. In our current experiment, wheat plants in drought treatment were grown at this water level up to maturity for the first time. Adjustment of the drought stress level lasting until maturity might yield better differentiation of contrasting genotypes in future studies on the platform.

\subsection{Drought Affects Gene Expression}

Signaling pathways of drought stress in plants involve several molecules, i.e., TFs, enzymes, functional proteins, molecular chaperones, and metabolites [27]. One of the most responsive elements are transcription factors $(\mathrm{TF})$, which are key regulatory proteins, and play their role in activating or repressing gene expression and regulating many biological processes. Many TF genes are affected by drought, including members of the NAC family, dehydration-responsive element-binding (DREB) factors. 
Here, we analyzed the expression of selected drought-associated TFs in the two wheat cultivars under drought stress condition. Wheat orthologues of the Arabidopsis gene JUB1/ANAC042, as well as TaNAC7 transcripts of the three chromosome copies A, B, and D showed increased expression in the drought tolerant cultivar, but no significant changes in the sensitive cultivar Condor. Meanwhile, related to NAC55, only NAC55A increased its expression in Condor, while $N A C 55 B$ and $D$ were repressed in Wadielniel. Induction of the expression of NAC TFs upon abiotic stresses was reported in different plant species [28-31]. For example, Thirumalaikumar et al. (2018) showed that expression of SIJUB1 in tomato is strongly induced upon treatment with $\mathrm{H}_{2} \mathrm{O}_{2}, \mathrm{NaCl}$, $\mathrm{PEG}$, and dehydration, indicating a role for this TF in the regulation of abiotic stress response networks in this plant, and concluded that JUB1 is a positive regulator of the response to drought in tomato [30].

In our study, the drought tolerant wheat cultivar Wadielniel exhibited an upregulation of TaPEPKR2, while no change was recorded for the drought sensitive cultivar Condor. According to Zang et al. (2018), the expression of TaPEPKR2 mRNA is induced by heat and $20 \%$ PEG treatment in wheat. Moreover, wheat plants overexpressing TaPEPKR2 present an enhanced response to heat and drought treatments [32]. Protein kinases regulate key aspects of cellular function, including responses to external signals [32,33].

Further, our data showed that the expression level of P5CS in tolerant cultivar (Wadielniel) was significantly higher, as compared to Condor. On the other hand, the expression level was significantly reduced when under drought stress conditions. Interestingly, we noticed that the induction of higher P5CS expression preceded the accumulation of proline under drought stress. Similarly, P5CS gene upregulation under drought stress has also been observed in wheat [34-37]. It is clear that plants overexpressing P5CS accumulate more proline than the control plants and are tolerant to osmotic stress [38]. Here, we only highlighted a few genes that might regulate the responses to drought stress in wheat, but further experimental work is needed to assess their roles in improving drought tolerance.

\subsection{Drought Stress Produces Drastic Metabolic Changes}

Metabolites play a major role in drought tolerance, as some of them have been considered as signaling molecules [10]. GC-MS is one of the major analytical tools in metabolomics to detect, identify, and analyze small molecules. In this study, we used metabolomic analysis to study the response of wheat cultivars to drought stress. A total of 42 metabolites in Condor and 26 in Wadielniel were significantly changed under drought stress conditions. The most significant changes occurred for amino acids, organic acids, and sugars. Proline, 4-hydroxy proline, valine, and glutamine, which are known to protect plants against abiotic stress, were more abundant in the drought treatments. Similarly, increased levels of amino acids were recorded under drought stress in other wheat studies $[11,12,39]$. Arginine, histidine, lysine, glycine, and $\beta$-alanine occurred at higher abundances in the drought sensitive cultivar Condor. The increase in these amino acids probably resulted from enhanced stress-induced protein breakdown or the inhibition of protein biosynthesis [40].

The most significantly changed metabolite was proline. Dramatic increases of proline levels under water-deficit conditions were previously found in wheat and maize cultivars of differing drought tolerance [41]. Proline acts as an osmolyte for osmotic adjustment and contributes to stabilizing sub-cellular structures, preventing oxidative burst, and accounting for higher drought tolerance [42].

Organic acids play an important role in energy production. They are precursors of amino acids, and may modulate plant adaptation to stress, including drought [43]. The current study shows that Wadielniel, the drought tolerant cultivar, accumulates high levels of glycolic acid, malic acid, fumaric acid, and pipecolic acid; these organic acids have important roles in the response to drought in wheat, and their levels can be related to drought tolerance. Kang et al. (2019) found that the accumulation of some organic acids, including glycolic acid, could contribute to greater capacity of some genotypes of wheat to manage drought stress [44]. For example, Fernie and Martinoia (2009) stated that besides 
being an essential storage carbon molecule during drought, malate has also a notable role in $\mathrm{pH}$ balancing and stomatal function [45]. Besides organic acids, some sugars showed high content upon drought. Sucrose had a higher content in the drought tolerant cultivar. A previous study has shown a high amount of sucrose in a drought-tolerant wheat genotype under drought stress [11]; it has been demonstrated that the presence of monosaccharides enables plants to stimulate efficient defense mechanisms $[46,47]$. Quinic acid as well as myo-instol were significantly reduced under drought stress in both cultivars. Correia et al. (2018) and Obata et al. (2015), unlike what was observed under drought stress in this study, found that heat and drought stress activated the shikimic acid pathway, and increased myo-inositol levels in maize and Eucalyptus globulus, respectively [10,48].

Another response to different stresses is the change in the composition of membrane lipids, which is highly variable depending on the stress and the species. We observed a general decrease in phosphatidylcholine (PC) and phosphatidylethanolamine (PE) on both cultivars subjected to drought stress. This pattern is similar in olive tree [49] and in wheat seedlings [50] treated with polyethylene glycol (PEG), which mimics the drought stress, that also present a decrease in PC and PE content upon drought stress. PC is the main substrate of phospholipase $\mathrm{D} \alpha$ (PLD) and alteration on its expression would change the membrane composition. Arabidopsis plants overexpressing wheat PLD $\alpha$ present a better response to drought than the wild-type plants [51]. Phospholipids as principal components of the cell membrane play a vital role for maintaining its stability. A decrease on PC and $P E$ will result in an unstable membrane with an increased ion permeability [52]. We also observed a higher concentration of digalactosyl-diacylglycerol (DGCG), similar to that found in maize [53], as well as in wheat seedlings [50]. This higher concentration of DGCG is a common strategy in plants to preserve membrane stability [54]. The results presented here provided a list of metabolites that play significant roles to enhance drought tolerance in wheat cultivars, and could be potential biomarkers for drought-stress responses.

\section{Conclusions}

Collectively, our results suggest that the selected drought-tolerant wheat cultivar Wadielniel has a greater capacity in regulating water deficit stress than the drought-sensitive cultivar Condor. As suggested by an enhanced physiological response supported by upregulating regulatory genes and producing more sugars, organic acids and important amino acids in shoots, which enable the plant to maintain growth under water deficit stress conditions. Those results enhance the knowledge on wheat responses to this stress, which cause severe yield loses and might be used as potential crop improvement in breeding programs.

\section{Materials and Methods}

\subsection{Plant Material and Water Deficit Stress Experiment}

Two wheat (Triticum aestivum L.) cultivars with contrasting drought response were used in this work. Wadielniel is an Egyptian cultivar (Giza 160) and presents great drought resistance, while Condor is less resistant. Both cultivars are extensively used in Sudan since 1987 and 1979, respectively [55]. Five plants per genotype at DAS 22 (T0) and five per genotype and treatment at T2 (DAS 59) were phenotyped in an experiment on a precision phenotyping system and used for genetic and metabolic analysis.

Plants were grown on the phenotyping platform (LemnaTec-Scanalyzer 3D system; LemnaTec $\mathrm{GmbH}$, Aachen, Germany) located in a controlled greenhouse at IPK Gatersleben $\left(51^{\circ} 49^{\prime} 23^{\prime \prime} \mathrm{N}, 11^{\circ} 17^{\prime} 13^{\prime \prime} \mathrm{E}, 112 \mathrm{~m}\right.$ a.s.1.). Plants were transported automatically to im-aging chambers equipped with top and side view RGB and fluorescence cameras, while a balance-watering station enabled controlled watering [56]. Each pot was filled in a standardized manner with Klaßman number two substrate [57] and with $7 \mathrm{~g}$ fertilizer $\left(19 \% \mathrm{~N}, 9 \% \mathrm{P}_{2} \mathrm{O}_{5}\right.$ and $\left.10 \% \mathrm{~K}_{2} \mathrm{O}\right)$, and placed on the platform. Two seeds per pot were sown, and seedlings thinned out to one plant per pot at DAS 7. Plants were subjected to drought reducing the watering level to 20\% (PAW) content, 23 days after sowing (DAS). This level 
was selected based on previous studies in barley, where this water content stopped barley growth [18]. Control plants were maintained at $70 \%$ PAW and plants were watered and imaged daily from side and top view. Greenhouse lights were set to a day length of $15 \mathrm{~h}$, while temperature was changed along the experiment growth period: (i) from sowing until 22 DAS (T0) $18 / 16^{\circ} \mathrm{C}$ day/night (ii) from 23 DAS to 61 DAS $20 / 16^{\circ} \mathrm{C}$ and (iii) from 62 DAS to maturity at $24 / 20^{\circ} \mathrm{C}$. Pots were automatically randomized by modi included in the software, several times a week.

Samples used for metabolomics and gene expression were harvested at DAS 22 (T0) as a control, as well as DAS 59 (T2) when the PAW had reduced in all plants to a stable level of $20 \%$ and all plants had reached the flowering stage. Samples were frozen in liquid nitrogen and stored at $-80^{\circ} \mathrm{C}$ until further use. At T0, the youngest fully developed leaf was harvested, at T2 the flag leaf from each main tiller and the leaf below were taken. An impression of the different growth response from both genotypes is presented in Figure 8.

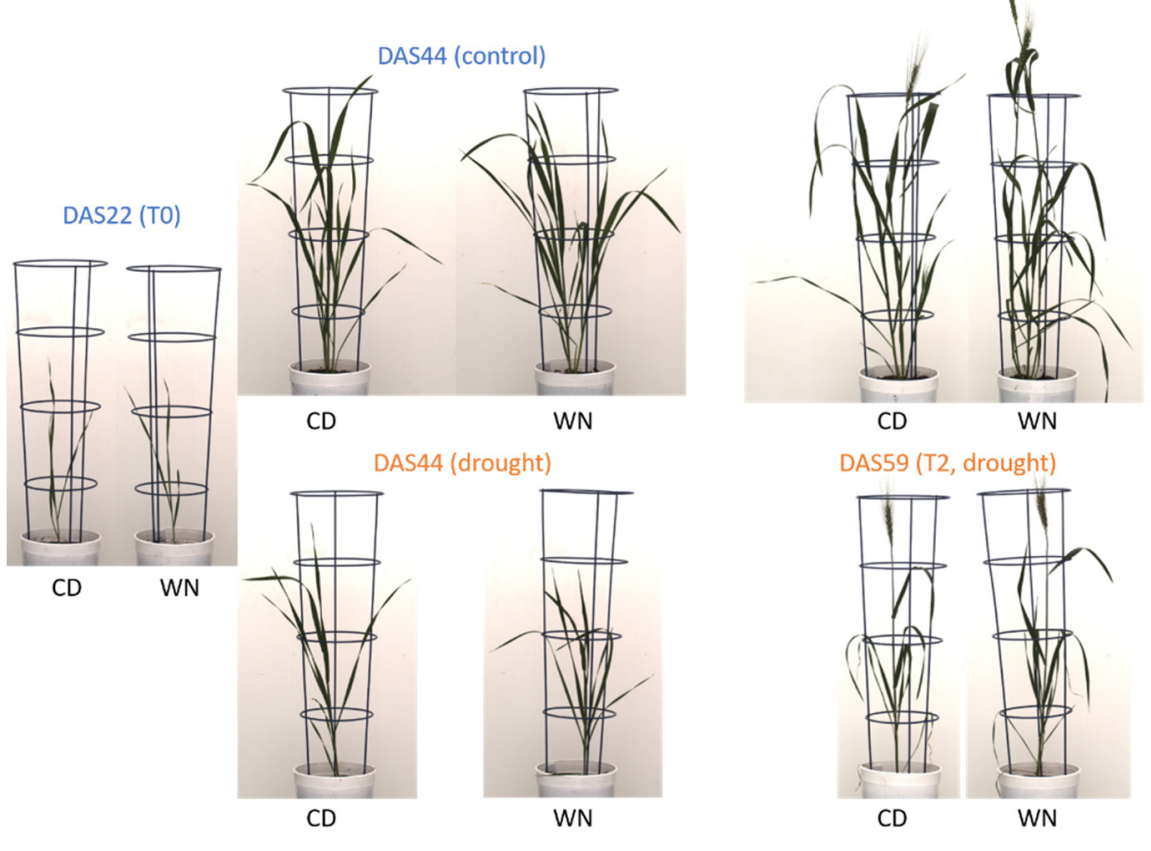

Figure 8. Individual plant images from RGB side view camera for plant at harvesting times T0 (DAS 22), DAS 44, and T2 (DAS 59) from Condor (CD) and Wadielniel (WN).

Using these photography's RGB side view images, we determined the day of heading (BBCH 55, half of the ear is out of the flag leaf) [17], the number of tillers, as well as the number of ears at DAS 71, 85, and 98 . The number of tiller was counted manually before and during drought stress at DAS 22 (T0), 44 and 53. After flowering, the number of ears was determined by visual inspection of RGB side view images at DAS 71, 85, and 98. At maturity, we determined plant height excluding awns, the length of ear and awns (of the main ear) the length of peduncle, and the length of the last internode. We determined the weight of total above ground biomass, then threshed the plant and evaluated the grain weight, then calculated the harvest index and the straw weight. Further, we determined the total number of seeds (whole plant and main ear) and using the Seed Analyzer "Marvin" (GTA Sensorik GmbH, Neubrandenburg, Germany), we measured the Thousand kernel weight (TKW), average seed area, length, and width. The number of spikelets of the main ear were also counted and we calculated the number of seeds per spikelet. 


\subsection{Gene Expression Analysis}

Total RNA was extracted using Trizol reagent (Life Technologies) following manufacturer instruction, and quantified using a Nano-Drop 8000 spectrophotometer. cDNA was synthesized from $300 \mathrm{ng}$ RNA using Superscript III reverse transcriptase (Invitrogen, http:/ /www.invitrogen.com/, accessed on 8 December 2021), with oligo (dT) primers, dNTPs $(10 \mathrm{~mm})$ and RT buffer, and incubated at $65^{\circ} \mathrm{C}$ for $5 \mathrm{~min}$. After Superscript III reverse transcriptase, Superscript III buffer and DTT and were added, and the mixture was incubated at $42^{\circ} \mathrm{C}$ for $1 \mathrm{~h}$, followed by $10 \mathrm{~min}$ at $70^{\circ} \mathrm{C}$. Using SYBR Green (TaqMan) fluorescent dye, qRT-PCR reaction were performed as described in [58]. PCR was performed using an ABI PRISM 7900HT sequence detection system (Applied Biosystems), using at least five biological replicates and the TaACTIN gene as control. The qPCR reactions were followed the recommended thermal profile: $95^{\circ} \mathrm{C}$ for $10 \mathrm{~min}$, then 40 cycles of $95^{\circ} \mathrm{C}$ for $15 \mathrm{~s}, 60{ }^{\circ} \mathrm{C}$ for $1 \mathrm{~min}$, and $72{ }^{\circ} \mathrm{C}$ for $30 \mathrm{~s}$, and a final cycle of rapid heating to $95{ }^{\circ} \mathrm{C}$ to denature the DNA, followed by cooling to $55^{\circ} \mathrm{C}$ for the melting curve. The relative levels of RNA for each gene were calculated from cycle threshold values according to the $40-\Delta \mathrm{Ct}$ method according to [59]. The primers used and gene numbers are listed in Table S2.

\subsection{Metabolite Profiling}

Extraction of metabolites was performed in accordance with [60]. Briefly, $100 \mathrm{mg}$ of fresh material was extracted with $1 \mathrm{~mL}$ of methyl-tert-butyl-ester:methanol (3:1), followed by a phase separation adding $\mathrm{H}_{2} \mathrm{O}: \mathrm{MeOH}(3: 1 v / v)$. For lipids analysis, $250 \mu \mathrm{L}$ from the aqueous phase were taken and dried under vacuum. The dried residue was resuspended in $100 \mu \mathrm{L}$ of UPLC-grade acetonitrile:isopropanol (70:30) mixture. From that, $2 \mu \mathrm{L}$ were injected individually on Acquity UPLC system using an RP C8 column and analyzed by MS [61]. The samples were measured in positive and negative ionization mode. The mass spectra were acquired using an Orbitrap high-resolution mass spectrometer: Fouriertransform mass spectrometer (FT-MS) coupled with a linear ion trap (LTQ) Orbitrap XL (ThermoFisher Scientific, Waltham, MA, USA, https:/ / www.thermofisher.com, accessed on 8 December 2021). On the other hand, $100 \mu \mathrm{L}$ from the organic phase were dried for primary metabolite analysis. The polar fraction was dried under vacuum, and the residue was derivatized for $120 \mathrm{~min}$ at $37^{\circ} \mathrm{C}$ (in $40 \mu \mathrm{L}$ of $20 \mathrm{mg} \mathrm{mL}^{-\mathrm{L}}$ methoxyamine hydrochloride in pyridine), followed by a $30 \mathrm{~min}$ treatment at $37^{\circ} \mathrm{C}$ with $70 \mu \mathrm{L}$ of MSTFA [62]. An autosampler Gerstel Multi-Purpose system (Gerstel GmbH \& Co.KG, Mülheim an der Ruhr, Germany) was used to inject the samples to a chromatograph coupled to a time-offlight mass spectrometer (GC-MS) system (Leco Pegasus HT TOF-MS (LECO Corporation, St. Joseph, MI, USA). Helium was used as carrier gas at a constant flow rate of $2 \mathrm{~mL} / \mathrm{s}$, and gas chromatography was performed on a $30 \mathrm{~m}$ DB- 35 column. The injection temperature was $230{ }^{\circ} \mathrm{C}$ and the transfer line and ion source were set to $250{ }^{\circ} \mathrm{C}$. The initial temperature of the oven $\left(85^{\circ} \mathrm{C}\right)$ increased at a rate of $15^{\circ} \mathrm{C} / \mathrm{min}$ up to a final temperature of $360^{\circ} \mathrm{C}$. After a solvent delay of $180 \mathrm{~s}$, mass spectra were recorded at 20 scans s $^{-1}$ with $m / z 70-600$ scanning range. Chromatograms and mass spectra were evaluated by using Chroma TOF 4.5 (Leco) and TagFinder 4.2 software.

Metabolite data correlation was analyzed using the website MetaboAnalyst [63] and Expressionist Analyst 14.0.5 (Genedata, Basel, Switzerland) (https:/ /www.genedata.com/ products/expressionist, accessed on 8 December 2021). Univariate analysis (two paired $t$-test) was applied to calculate the statistical significance and fold change of the metabolites between two time points (stress over control). The supervised multivariate method, PLSDA (partial least squares-discriminant analysis) was used to maximize the metabolome difference between the control and stress treated samples, as well as the difference between two cultivars. The relative importance of each metabolite to the PLS-DA model was checked using variable importance in projection (VIP). Metabolites with VIP $>1.0$ were considered as differential metabolites for group discrimination. Heat maps were generated based on $\log _{2}$-transformed fold change values. 


\subsection{Statistical Analysis}

Statistical significance was tested with a Student's t-test using Graphpad 9.0. Differences were calculated either between conditions in the same cultivar or between cultivars in different conditions, and are stated in each figure or table.

Supplementary Materials: The following are available online at https:/ / www.mdpi.com/article/10 $.3390 /$ ijms222413287/s1.

Author Contributions: Investigation, H.E.F., K.N. and S.A.; resources, K.N., S.B. and A.R.F.; data curation, F.J.M.R. and S.A.; writing-original draft preparation, H.E.F. and F.J.M.R.; writing-review and editing, F.J.M.R., S.A. and S.B.; project administration, K.N., S.B., A.R.F. and S.A.; funding acquisition, H.E.F., K.N., S.B., A.R.F. and S.A. All authors have read and agreed to the published version of the manuscript.

Funding: F.J.M.R. acknowledges Deutsche Forschungsgemeinschaft for the project FE 552/39-1. S.B. acknowledges funding by the Max Planck Institute of Molecular Plant Physiology. A.R.F. and S.A acknowledge European Union's Horizon 2020 research and innovation programme, project PlantaSYST (SGA-CSA No. 739582 under FPA No. 664620).

Institutional Review Board Statement: Not applicable.

Informed Consent Statement: Not applicable.

Data Availability Statement: All the data reported are found either in the manuscript or in the Supplementary Material of the article.

Acknowledgments: Author thanks IPK gardener team of Kathrin Gramel-Koch, Ingo Mücke, and Ute Krajewski for the support with the experimental work on the phenotyping platform.

Conflicts of Interest: The authors declare no conflict of interest. The funders had no role in the design of the study; in the collection, analyses, or interpretation of data; in the writing of the manuscript, or in the decision to publish the results.

\section{References}

1. Shewry, P.R.; Hey, S.J. The contribution of wheat to human diet and health. Food Energy Secur. 2015, 4, 178-202. [CrossRef]

2. Brisson, N.; Gate, P.; Gouache, D.; Charmet, G.; Oury, F.X.; Huard, F. Why are wheat yields stagnating in Europe? A comprehensive data analysis for France. Field Crop. Res. 2010, 119, 201-212. [CrossRef]

3. Kalra, N.; Chakraborty, D.; Sharma, A.; Rai, H.K.; Jolly, M.; Chander, S.; Kumar, P.R.; Bhadraray, S.; Barman, D.; Mittal, R.B.; et al. Effect of increasing temperature on yield of some winter crops in northwest India. Curr. Sci. 2008, 94, 82-88.

4. Zampieri, M.; Ceglar, A.; Dentener, F.; Toreti, A. Wheat yield loss attributable to heat waves, drought and water excess at the global, national and subnational scales. Environ. Res. Lett. 2017, 12, 064008. [CrossRef]

5. Ihsan, M.Z.; El-Nakhlawy, F.S.; Ismail, S.M.; Fahad, S.; Daur, I. Wheat Phenological Development and Growth Studies as Affected by Drought and Late Season High Temperature Stress under Arid Environment. Front. Plant Sci. 2016, 7, 795. [CrossRef] [PubMed]

6. Zhou, G.A.; Chang, R.Z.; Qiu, L.J. Overexpression of soybean ubiquitin-conjugating enzyme gene GmUBC2 confers enhanced drought and salt tolerance through modulating abiotic stress-responsive gene expression in Arabidopsis. Plant Mol. Biol. 2010, 72 , 357-367. [CrossRef] [PubMed]

7. Kulkarni, M.; Soolanayakanahally, R.; Ogawa, S.; Uga, Y.; Selvaraj, M.G.; Kagale, S. Drought Response in Wheat: Key Genes and Regulatory Mechanisms Controlling Root System Architecture and Transpiration Efficiency. Front. Chem. 2017, 5, 106. [CrossRef]

8. Urbanaviciute, I.; Bonfiglioli, L.; Pagnotta, M.A. One Hundred Candidate Genes and Their Roles in Drought and Salt Tolerance in Wheat. Int. J. Mol. Sci. 2021, 22, 6378. [CrossRef]

9. Budak, H.; Hussain, B.; Khan, Z.; Ozturk, N.Z.; Ullah, N. From Genetics to Functional Genomics: Improvement in Drought Signaling and Tolerance in Wheat. Front. Plant Sci. 2015, 6, 1012. [CrossRef]

10. Obata, T.; Fernie, A.R. The use of metabolomics to dissect plant responses to abiotic stresses. Cell. Mol. Life Sci. 2012, 69, 3225-3243. [CrossRef] [PubMed]

11. Guo, X.; Xin, Z.; Yang, T.; Ma, X.; Zhang, Y.; Wang, Z.; Ren, Y.; Lin, T. Metabolomics Response for Drought Stress Tolerance in Chinese Wheat Genotypes (Triticum aestivum). Plants 2020, 9, 520. [CrossRef] [PubMed]

12. Ullah, N.; Yuce, M.; Neslihan Ozturk Gokce, Z.; Budak, H. Comparative metabolite profiling of drought stress in roots and leaves of seven Triticeae species. BMC Genom. 2017, 18, 969. [CrossRef] [PubMed]

13. Lopez-Perez, L.; Martinez-Ballesta Mdel, C.; Maurel, C.; Carvajal, M. Changes in plasma membrane lipids, aquaporins and proton pump of broccoli roots, as an adaptation mechanism to salinity. Phytochemistry 2009, 70, 492-500. [CrossRef] [PubMed] 
14. Liu, B.; Wang, X.; Li, K.; Cai, Z. Spatially Resolved Metabolomics and Lipidomics Reveal Salinity and Drought-Tolerant Mechanisms of Cottonseeds. J. Agric. Food Chem. 2021, 69, 8028-8037. [CrossRef]

15. Fazeli, F.; Ghorbanli, M.; Niknam, V. Effect of drought on biomass, protein content, lipid peroxidation and antioxidant enzymes in two sesame cultivars. Biol. Plant. 2007, 51, 98-103. [CrossRef]

16. Kapoor, D.; Bhardwaj, S.; Landi, M.; Sharma, A.; Ramakrishnan, M.; Sharma, A. The Impact of Drought in Plant Metabolism: How to Exploit Tolerance Mechanisms to Increase Crop Production. Appl. Sci. 2020, 10, 5692. [CrossRef]

17. Lancashire, P.D.; Bleiholder, H.; Vandenboom, T.; Langeluddeke, P.; Stauss, R.; Weber, E.; Witzenberger, A. A Uniform Decimal Code for Growth-Stages of Crops and Weeds. Ann. Appl. Biol. 1991, 119, 561-601. [CrossRef]

18. Dhanagond, S.; Liu, G.; Zhao, Y.; Chen, D.; Grieco, M.; Reif, J.; Kilian, B.; Graner, A.; Neumann, K. Non-Invasive Phenotyping Reveals Genomic Regions Involved in Pre-Anthesis Drought Tolerance and Recovery in Spring Barley. Front. Plant Sci. 2019, 10, 1307. [CrossRef]

19. Sehgal, A.; Sita, K.; Siddique, K.H.M.; Kumar, R.; Bhogireddy, S.; Varshney, R.K.; HanumanthaRao, B.; Nair, R.M.; Prasad, P.V.V.; Nayyar, H. Drought or/and Heat-Stress Effects on Seed Filling in Food Crops: Impacts on Functional Biochemistry, Seed Yields, and Nutritional Quality. Front. Plant Sci. 2018, 9, 1705. [CrossRef]

20. Mahrookashani, A.; Siebert, S.; Huging, H.; Ewert, F. Independent and combined effects of high temperature and drought stress around anthesis on wheat. J. Agron. Crop. Sci. 2017, 203, 453-463. [CrossRef]

21. Li, L.; Mao, G.; Wang, J.Y.; Chang, X.P.; Reynolds, M.; Jing, R.L. Genetic dissection of drought and heat-responsive agronomic traits in wheat. Plant Cell Environ. 2019, 42, 2540-2553. [CrossRef] [PubMed]

22. Duggan, B.L.; Domitruk, D.R.; Fowler, D.B. Yield component variation in winter wheat grown under drought stress. Can. J. Plant Sci. 2000, 80, 739-745. [CrossRef]

23. Bowne, J.B.; Erwin, T.A.; Juttner, J.; Schnurbusch, T.; Langridge, P.; Bacic, A.; Roessner, U. Drought Responses of Leaf Tissues from Wheat Cultivars of Differing Drought Tolerance at the Metabolite Level. Mol. Plant 2012, 5, 418-429. [CrossRef]

24. Shavrukov, Y.; Zhumalin, A.; Serikbay, D.; Botayeva, M.; Otemisova, A.; Absattarova, A.; Sereda, G.; Sereda, S.; Shvidchenko, V.; Turbekova, A.; et al. Expression Level of the DREB2-Type Gene, Identified with Amplifluor SNP Markers, Correlates with Performance, and Tolerance to Dehydration in Bread Wheat Cultivars from Northern Kazakhstan. Front. Plant Sci. 2017, 8, 1736. [CrossRef]

25. Barnabas, B.; Jager, K.; Feher, A. The effect of drought and heat stress on reproductive processes in cereals. Plant Cell Environ. 2008, 31, 11-38. [CrossRef]

26. Khan, N.; Nazar, R.; Iqbal, N.; Anjum, N. Phytohormones and Abiotic Stress Tolerance in Plants; Springer: Berlin/Heidelberg, Germany, 2012.

27. Song, X.M.; Li, Y.; Hou, X.L. Genome-wide analysis of the AP2/ERF transcription factor superfamily in Chinese cabbage (Brassica rapa ssp pekinensis). BMC Genom. 2013, 14, 573. [CrossRef]

28. Tran, L.S.P.; Nakashima, K.; Sakuma, Y.; Simpson, S.D.; Fujita, Y.; Maruyama, K.; Fujita, M.; Seki, M.; Shinozaki, K.; YamaguchiShinozaki, K. Isolation and functional analysis of Arabidopsis stress-inducible NAC transcription factors that bind to a droughtresponsive cis-element in the early responsive to dehydration stress 1 promoter. Plant Cell 2004, 16, 2481-2498. [CrossRef]

29. Mao, H.D.; Li, S.M.; Wang, Z.X.; Cheng, X.X.; Li, F.F.; Mei, F.M.; Chen, N.; Kang, Z.S. Regulatory changes in TaSNAC8-6A are associated with drought tolerance in wheat seedlings. Plant Biotechnol. J. 2020, 18, 1078-1092. [CrossRef]

30. Thirumalaikumar, V.P.; Devkar, V.; Mehterov, N.; Ali, S.; Ozgur, R.; Turkan, I.; Mueller-Roeber, B.; Balazadeh, S. NAC transcription factor JUNGBRUNNEN1 enhances drought tolerance in tomato. Plant Biotechnol. J. 2018, 16, 354-366. [CrossRef] [PubMed]

31. Huang, Q.J.; Wang, Y.; Li, B.; Chang, J.L.; Chen, M.J.; Li, K.X.; Yang, G.X.; He, G.Y. TaNAC29, a NAC transcription factor from wheat, enhances salt and drought tolerance in transgenic Arabidopsis. BMC Plant Biol. 2015, 15, 268. [CrossRef] [PubMed]

32. Zang, X.S.; Geng, X.L.; He, K.X.; Wang, F.; Tian, X.J.; Xin, M.M.; Yao, Y.Y.; Hu, Z.R.; Ni, Z.F.; Sun, Q.X.; et al. Overexpression of the Wheat (Triticum aestivum L.) TaPEPKR2 Gene Enhances Heat and Dehydration Tolerance in Both Wheat and Arabidopsis. Front. Plant Sci. 2018, 9, 1710. [CrossRef]

33. Krugman, T.; Chague, V.; Peleg, Z.; Balzergue, S.; Just, J.; Korol, A.B.; Nevo, E.; Saranga, Y.; Chalhoub, B.; Fahima, T. Multilevel regulation and signalling processes associated with adaptation to terminal drought in wild emmer wheat. Funct. Integr. Genom. 2010, 10, 167-186. [CrossRef] [PubMed]

34. Lee, J.; Lee, H.; Noh, E.K.; Park, M.; Park, H.; Kim, J.H.; Kim, I.C.; Yim, J.H. Expression analysis of transcripts responsive to osmotic stress in Deschampsia antarctica Desv. Genes Genom. 2014, 36, 283-291. [CrossRef]

35. Maghsoudi, K.; Emam, Y.; Niazi, A.; Pessarakli, M.; Arvin, M.J. P5CS expression level and proline accumulation in the sensitive and tolerant wheat cultivars under control and drought stress conditions in the presence/absence of silicon and salicylic acid. J. Plant Interact. 2018, 13, 461-471. [CrossRef]

36. Dudziak, K.; Zapalska, M.; Borner, A.; Szczerba, H.; Kowalczyk, K.; Nowak, M. Analysis of wheat gene expression related to the oxidative stress response and signal transduction under short-term osmotic stress. Sci. Rep. 2019, 9, 2743. [CrossRef] [PubMed]

37. Itam, M.; Mega, R.; Tadano, S.; Abdelrahman, M.; Matsunaga, S.; Yamasaki, Y.; Akashi, K.; Tsujimoto, H. Metabolic and physiological responses to progressive drought stress in bread wheat. Sci. Rep. 2020, 10, 17189. [CrossRef]

38. Vendruscolo, E.C.G.; Schuster, I.; Pileggi, M.; Scapim, C.A.; Correa Molinari, H.B.; Marur, C.J.; Esteves Vieira, L.G. Stress-induced synthesis of proline confers tolerance to water deficit in transgenic wheat. J. Plant Physiol. 2007, 164, 1367-1376. [CrossRef] [PubMed] 
39. Marcek, T.; Hamow, K.A.; Vegh, B.; Janda, T.; Darko, E. Metabolic response to drought in six winter wheat genotypes. PLoS ONE 2019, 14, e0212411. [CrossRef]

40. Nelson, C.J.; Li, L.; Millar, A.H. Quantitative analysis of protein turnover in plants. Proteomics 2014, 14, 579-592. [CrossRef]

41. Michaletti, A.; Naghavi, M.R.; Toorchi, M.; Zolla, L.; Rinalducci, S. Metabolomics and proteomics reveal drought-stress responses of leaf tissues from spring-wheat. Sci. Rep. 2018, 8, 5710. [CrossRef] [PubMed]

42. Hayat, S.; Hayat, Q.; Alyemeni, M.N.; Wani, A.S.; Pichtel, J.; Ahmad, A. Role of proline under changing environments: A review. Plant Signal. Behav. 2012, 7, 1456-1466. [CrossRef]

43. Jin, R.; Wang, Y.P.; Liu, R.J.; Gou, J.B.; Chan, Z.L. Physiological and Metabolic Changes of Purslane (Portulaca oleracea L.) in Response to Drought, Heat, and Combined Stresses. Front. Plant Sci. 2016, 6, 1123. [CrossRef]

44. Kang, Z.; Babar, M.A.; Khan, N.; Guo, J.; Khan, J.; Islam, S.; Shrestha, S.; Shahi, D. Comparative metabolomic profiling in the roots and leaves in contrasting genotypes reveals complex mechanisms involved in post-anthesis drought tolerance in wheat. PLoS ONE 2019, 14, e0213502. [CrossRef]

45. Fernie, A.R.; Martinoia, E. Malate. Jack of all trades or master of a few? Phytochemistry 2009, 70, 828-832. [CrossRef] [PubMed]

46. Morkunas, I.; Narozna, D.; Nowak, W.; Samardakiewicz, S.; Remlein-Starosta, D. Cross-talk interactions of sucrose and Fusarium oxysporum in the phenylpropanoid pathway and the accumulation and localization of flavonoids in embryo axes of yellow lupine. J. Plant Physiol. 2011, 168, 424-433. [CrossRef]

47. Rezaul, I.M.; Feng, B.H.; Chen, T.T.; Fu, W.M.; Zhang, C.X.; Tao, L.X.; Fu, G.F. Abscisic acid prevents pollen abortion under high-temperature stress by mediating sugar metabolism in rice spikelets. Physiol. Plant. 2019, 165, 644-663. [CrossRef]

48. Correia, B.; Hancock, R.D.; Amaral, J.; Gomez-Cadenas, A.; Valledor, L.; Pinto, G. Combined Drought and Heat Activates Protective Responses in Eucalyptus globulus That Are Not Activated When Subjected to Drought or Heat Stress Alone. Front. Plant Sci. 2018, 9, 819. [CrossRef] [PubMed]

49. Guerfel, M.; Baccouri, O.; Boujnah, D.; Zarrouk, M. Changes in lipid composition, water relations and gas exchange in leaves of two young 'Chemlali' and 'Chetoui' olive trees in response to water stress. Plant Soil 2008, 311, 121-129. [CrossRef]

50. Wang, Y.; Zhang, X.; Huang, G.; Feng, F.; Liu, X.; Guo, R.; Gu, F.; Zhong, X.; Mei, X. Dynamic changes in membrane lipid composition of leaves of winter wheat seedlings in response to PEG-induced water stress. BMC Plant Biol. 2020, 20, 84. [CrossRef]

51. Wang, J.; Ding, B.; Guo, Y.; Li, M.; Chen, S.; Huang, G.; Xie, X. Overexpression of a wheat phospholipase D gene, TaPLDalpha, enhances tolerance to drought and osmotic stress in Arabidopsis thaliana. Planta 2014, 240, 103-115. [CrossRef]

52. Welti, R.; Li, W.Q.; Li, M.Y.; Sang, Y.M.; Biesiada, H.; Zhou, H.E.; Rajashekar, C.B.; Williams, T.D.; Wang, X.M. Profiling membrane lipids in plant stress responses-Role of phospholipase D alpha in freezing-induced lipid changes in Arabidopsis. J. Biol. Chem. 2002, 277, 31994-32002. [CrossRef] [PubMed]

53. Chen, D.Q.; Wang, S.W.; Qi, L.Y.; Yin, L.N.; Deng, X.P. Galactolipid remodeling is involved in drought-induced leaf senescence in maize. Environ. Exp. Bot. 2018, 150, 57-68. [CrossRef]

54. Moellering, E.R.; Muthan, B.; Benning, C. Freezing Tolerance in Plants Requires Lipid Remodeling at the Outer Chloroplast Membrane. Science 2010, 330, 226-228. [CrossRef]

55. Saunders, D.A. Wheat in Heat-stressed Environments: Irrigated, Dry Areas, and Rice-wheat Farming Systems. In Proceedings of the International Conferences: Wheat in Hot, Dry, Irrigated Environments, Wad Medani, Sudan, 1-4 February 1993.

56. Junker, A.; Muraya, M.M.; Weigelt-Fischer, K.; Arana-Ceballos, F.; Klukas, C.; Melchinger, A.E.; Meyer, R.C.; Riewe, D.; Altmann, T. Optimizing experimental procedures for quantitative evaluation of crop plant performance in high throughput phenotyping systems. Front. Plant Sci. 2014, 5, 770. [CrossRef]

57. Neumann, K.; Klukas, C.; Friedel, S.; Rischbeck, P.; Chen, D.; Entzian, A.; Stein, N.; Graner, A.; Kilian, B. Dissecting spatiotemporal biomass accumulation in barley under different water regimes using high-throughput image analysis. Plant Cell Environ. 2015, 38, 1980-1996. [CrossRef]

58. Balazadeh, S.; Riano-Pachon, D.M.; Mueller-Roeber, B. Transcription factors regulating leaf senescence in Arabidopsis thaliana. Plant Biol. 2008, 10 (Suppl. 1), 63-75. [CrossRef]

59. Devkar, V.; Thirumalaikumar, V.P.; Xue, G.P.; Vallarino, J.G.; Tureckova, V.; Strnad, M.; Fernie, A.R.; Hoefgen, R.; Mueller-Roeber, B.; Balazadeh, S. Multifaceted regulatory function of tomato SITAF1 in the response to salinity stress. New Phytol. 2020, 225, 1681-1698. [CrossRef] [PubMed]

60. Salem, M.A.; Yoshida, T.; Perez de Souza, L.; Alseekh, S.; Bajdzienko, K.; Fernie, A.R.; Giavalisco, P. An improved extraction method enables the comprehensive analysis of lipids, proteins, metabolites and phytohormones from a single sample of leaf tissue under water-deficit stress. Plant J. 2020, 103, 1614-1632. [CrossRef]

61. Hummel, J.; Segu, S.; Li, Y.; Irgang, S.; Jueppner, J.; Giavalisco, P. Ultra performance liquid chromatography and high resolution mass spectrometry for the analysis of plant lipids. Front. Plant Sci. 2011, 2, 54. [CrossRef]

62. Lisec, J.; Schauer, N.; Kopka, J.; Willmitzer, L.; Fernie, A.R. Gas chromatography mass spectrometry-based metabolite profiling in plants. Nat. Protoc. 2006, 1, 387-396. [CrossRef] [PubMed]

63. Pang, Z.; Chong, J.; Zhou, G.; De Lima Morais, D.A.; Chang, L.; Barrette, M.; Gauthier, C.; Jacques, P.E.; Li, S.; Xia, J. MetaboAnalyst 5.0: Narrowing the gap between raw spectra and functional insights. Nucleic Acids Res. 2021, 49, W388-W396. [CrossRef] [PubMed] 